\title{
Ertragen widersprüchlicher und unvereinbarer Anforderungen - ein Teil der Wertschöpfung des Chefarztes
}

Richard O. Binswanger

* Aus stilistischen Gründen wird die männliche Form verwendet. Frauen sind ausdrücklich mitgemeint.

In den langen Jahren der Weiterbildung und oberärztlicher Tätigkeit waren Sie in Teams integriert. Sie gehörten dazu, schlossen Freundschaften, waren ein Teil des Ganzen. Jetzt sind Sie Chefarzt* geworden und plötzlich stehen Sie allein. Frère et cochon, c'est fini. Ihre Mitarbeiter und Kollegen sind nicht mehr Freunde, sondern Mitarbeiter und Kollegen. Natürlich kann und soll sich auch mit diesen ein freundschaftliches Verhältnis entwickeln. Letzteres ist aber stets den Interessen Ihrer Klinik und des Spitals unterzuordnen. Damit ist es prinzipiell bedroht. Sie sind plötz-

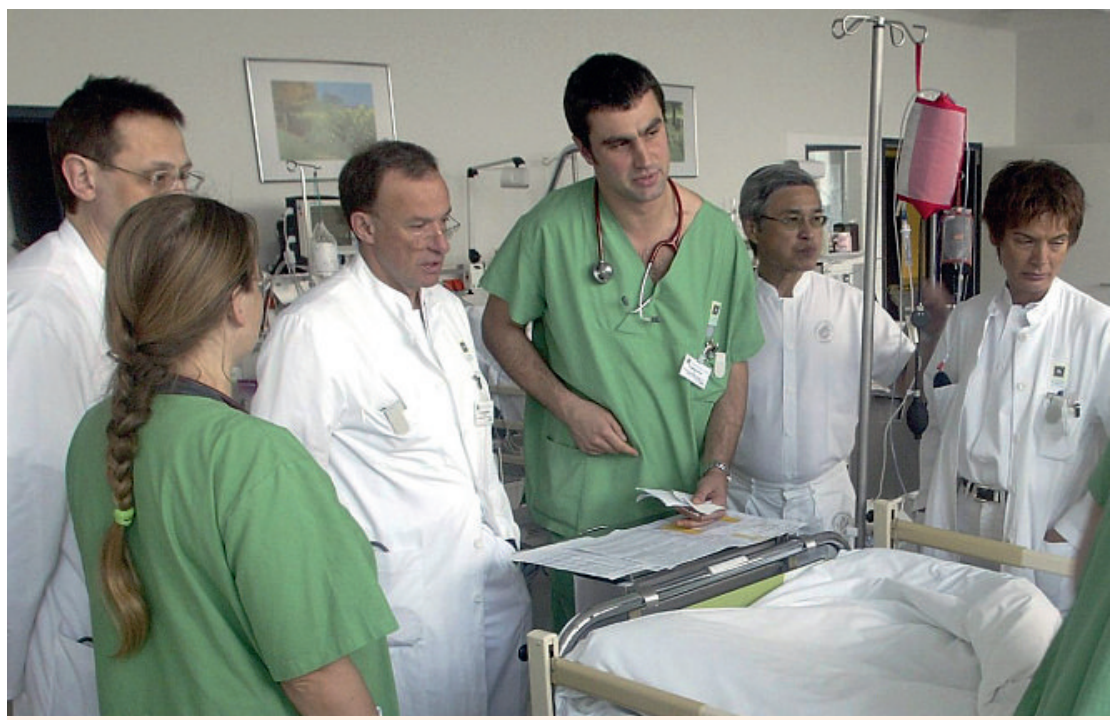

Chef sein, Kollege bleiben - schwer zu vereinbarende Anforderungen an einen Chefarzt.

Korrespondenz:

Dr. med. Richard O. Binswanger Radiologie und

Nuklearmedizin FMH

Führungsschule Bodensee

Münsterlingen

Oberer Seeweg 9

CH-8597 Landschlacht

r.binswanger@bluewin.ch

www.fsb-spital.ch lich allein und fühlen sich einsam. Das belastet. Ich selbst brauchte zwei Jahre, um die neue Situation zu verstehen und zu akzeptieren.

\section{Widersprüche und unvereinbare Anforderungen}

Dazu kommen widersprüchliche und unvereinbare Anforderungen, die an Sie gestellt werden. Sie und Ihre Mitarbeiter sollen erstklassige Medizin betreiben, und zwar bitte schön effizient und kostensparend. Dafür notwendige Investitionen und Personal werden eventuell gar nicht bewilligt. Der Patient soll im Mittelpunkt stehen. Ihre Mitarbeiter sollen also möglichst viel am Krankenbett und im Operationssaal arbeiten. Aber wehe, wenn sie ihren Papierkram nicht erledigen. Die Qualitätssicherung soll unmittelbar stattfinden, zwischen Ärzten in der praktischen Arbeit. Das ist aber nicht messbar. Deshalb haben sie messbare und verschriftlichte Resultate zu liefern, was überflüssige Bürokratie erzeugt. Und die reale Qualität doch nicht abbildet. Sie sollen von Ihren Mitarbeitern Höchstleistungen fordern und gleichzeitig deren Arbeitszeit begrenzen. Sie müssen das Interesse des Spitals über das Ihrer Klinik stellen und dafür Einschränkungen in Kauf nehmen.

\section{Und was ist am schlimmsten?}

Sie müssen schmerzliche Anordnungen und Forderungen vertreten und durchsetzen, die eventuell sogar Ihren eigenen Grundsätzen widersprechen. Sie müssen sich von Mitarbeitern trennen, obwohl das Ihnen grosse Qualen verursacht und Ihrem sozialen Gewissen widerspricht. Sie müssen ständig auch unangenehme Entscheidungen treffen, und zwar nicht nach Ihrem Gefühl sondern um der Funktionstüchtigkeit Ihrer Klinik willen.

\section{Und wozu das alles?}

Es geht darum, dass einer, und zwar Sie ganz allein, dies alles aushält, möglichst stoisch und gelassen, wenigstens nach aussen hin. Dass Sie Ihrer Klinik und Ihren Mitarbeitern diese Konflikte ersparen. Dass Sie in der Ungewissheit Richtlinien setzen, nach denen sich jeder zu verhalten hat. Das schafft die dringend notwendige Orientierung und die Ruhe, die Ihren Betrieb erst funktionsfähig machen. Und verhindert Ratlosigkeit und Streit.

\section{Ein Teil lhrer Wertschöpfung als Chefarzt}

Natürlich wurden Sie wegen Ihres herausragenden ärztlichen Könnens gewählt. Damit erbringen Sie aber nur einen Teil der Wertschöpfung, für die Sie ein hoffentlich angemessenes Einkommen erhalten. Zusätzlich sollen Sie führen und Orientierung vermitteln. Da die Anforderungen widersprüchlich und oft unvereinbar sind, muss einer allein diesen Konflikt aus- und ertragen. Die Übereinstimmung mit der Aufgabe herstellen. Das sind Sie. Sie schaffen damit einen Wert. Einen Teil der Wertschöpfung des Chefarztes. 